\title{
Optical properties of Poly-[2-methoxy-5-(2-ethyl-hexyloxy)-phenylene vinylene and its application in photovoltaic cells
}

\author{
P. M. Sirimanne* and E. V. A. Premalal
}

Nano-Science Laboratory, Institute of Fundamental Studies, Hantana Road, Kandy, Sri Lanka

\begin{abstract}
A conjugated polymer poly[2-methoxy-5-(2-ethyl-hexyloxy)-phenylene vinylene] (MEH-PPV) exhibits unique absorption band in the visible region due to electron transitions between nonlocalized bands and emits light in three different wavelength regions. Doping of iodine increases absorption in the visible region of polymer. MEH-PPV is used as a hole-conductor and a sensitizer in titana based solid-state photovoltaic cells. Maximum photocurrent of 1.3 $\mathrm{mAcm}^{-2}$ and voltage of about $543 \mathrm{mV}$ are observed for a photovoltaic cell with the polymer sensitizing layer. However, slightly higher photocurrent $\left(2.4 \mathrm{mAcm}^{-2}\right)$ with a decrement of voltage $(465 \mathrm{mV})$ is observed for a solid-state cell with a configuration of $\mathrm{TiO}_{2} \mid$ dye $\mid \mathrm{MEH}-$ $\mathrm{PPV} \mid \mathrm{I}_{2}$, under AM 1.5 conditions. Incident light to power conversion efficiency of these cells is about $0.6 \%$.
\end{abstract}

\section{INTRODUCTION}

Conjugated polymers have aroused blooming attraction due to their peculiar properties of higher absorption co-efficient, luminescent and sufficiently fast carrier mobility. For examples, poly phenylene vinylene (PPV) and its derivatives exhibit luminescence at red region of the visible spectrum [1,2]. An efficient separation of excitons is observed in combination of MEH-PPV with a material which has low electron affinity function [3]. In

\footnotetext{
* Corresponding author: psirimanne@hotmail.com
} 
addition, sufficient fast hole conductivity is observed in MEH-PPV [4,5]. These properties suggest capability of utilization of PPV and its derivatives in solid-state devices. We have made an attempt to utilize MEH-PPV as a sensitizer and a hole-conductor, in titana based photovoltaic cells. Photo-properties of $\mathrm{TiO}_{2}|\mathrm{MEH}-\mathrm{PPV}|$ electrolyte and $\mathrm{TiO}_{2} \mid$ dye $\mid \mathrm{MEH}-$ $\mathrm{PPV}\left|\mathrm{I}_{2}\right|$ graphite cells are studied and our primary observations are discussed.

\section{EXPERIMENTAL}

Meso-porous $\mathrm{TiO}_{2}$ films with thickness of $\sim 10 \mu \mathrm{m}$ were prepared by applying a colloidal solution of hydrolyzed titanium isopropoxide which contains $\mathrm{TiO}_{2}$ powder (P-25 Degussa, Japan) on preheated conducting glass plates (FTO) as descried elsewhere [6].

\subsection{Fabrication of photo-voltaic cells with MEH-PPV sensitizing layer}

MEH-PPV was embedded in porous matrix of $\mathrm{TiO}_{2}$ by a slow solvent evaporation technique. MEH-PPV in $\mathrm{CHCl}_{3}$ was used as the coating solution. $\mathrm{TiO}_{2} \mid \mathrm{MEH}-\mathrm{PPV}$ electrodes were allowed to dry at room temperature. An FTO electrode was attached to $\mathrm{TiO}_{2} \mid \mathrm{MEH}-\mathrm{PPV}$ electrode as the counter electrode. The electrolyte was spread in between two electrodes by capillary action. Standard $\mathrm{I}^{-} \mid \mathrm{I}_{3}{ }^{-}\left(\mathrm{E}_{\mathrm{o}}=0.53 \mathrm{~V}\right.$ vs NHE, [7]) redox-couple in acetonitrile was used as the electrolyte.

\subsection{Fabrication of photo-voltaic cells with MEH-PPV hole-conducting layer}

Dye [cis dithiocyanate-bis (2,2'-bipyridyl 4, 4'-dicarboxylate) ruthenium (II)] (hereafter abbreviated as N3) was coated on dried $\mathrm{TiO}_{2}$ electrodes by dipping in a dye solution of $3 \times 10^{-3} \mathrm{M}$, (in ethanol at $40^{\circ} \mathrm{C}$ ). Dye coated $\mathrm{TiO}_{2}$ electrodes were dried in a hot air stream followed by washing with ethanol. A thin layer of MEH-PPV was coated on sensitized $\mathrm{TiO}_{2}$ films as described in the previous section. $\mathrm{TiO}_{2}|\mathrm{~N} 3| \mathrm{MEH}-\mathrm{PPV}$ electrodes were allowed to dry at room temperature and then a thin layer of graphite was applied on the MEH-PPV layer followed by doping of iodine in the polymer film. An FTO electrode was attached to the graphite surface as the back contact of the cell. Cells were characterized under illumination of monochromatic and polychromatic light $\left(100 \mathrm{mWcm}^{-2}\right)$. 


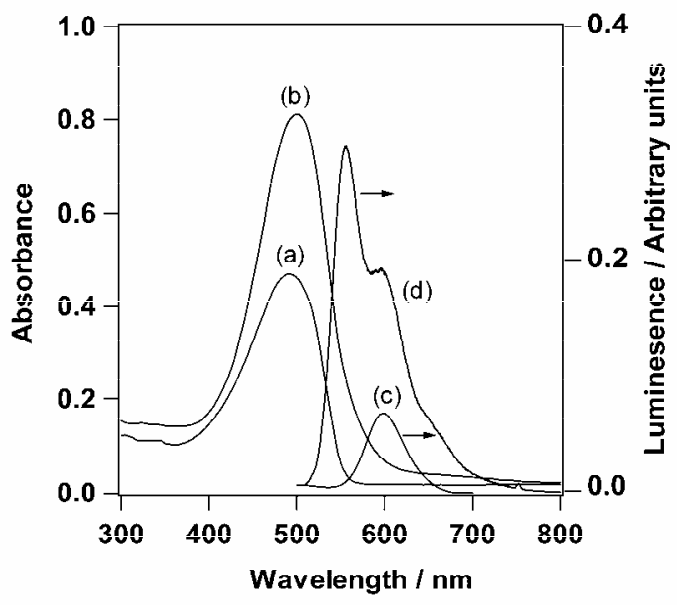

Fig. 1 Absorption spectrum of a MEH-PPV solution in chloroform (a) as obtained (without iodine treatment, $\left.10^{-3} \mathrm{M}\right)$, (b) after doping iodine in same solution, and emission spectra for MEH-PPV in chloroform different concentrations (c) $10^{-3} \mathrm{M}$ and (d) $10^{-5} \mathrm{M}$

\section{RESULTS AND DISCUSSION}

MEH-PPV absorbs visible light in the wavelength region of 400-575 $\mathrm{nm}$ with an optimal at $500 \mathrm{~nm}$ (curve a, Fig. 1). Electron transitions between non-localized bands $\left(\pi \rightarrow \pi^{*}\right)$ are responsible for this unique absorption band [8,9]. The onset of absorption mimics that band gap of MEH-PPV is $2.2 \mathrm{eV}$. This value agrees with Daoud et al's observations [5]. A clear enhancement of absorbance is observed by doping iodine in the polymer (curve b). Almost similar shapes in absorption spectra reveal that light doping does not make any significant influence in disordering of polymer chain. Similar result has been observed by introducing polystyrene in MEH-PPV [9]. It is known that MEH-PPV exhibits a strong emission band in the red portion of the visible spectrum. Luminescence spectrum of a solution of MEHPPV $\left(10^{-3} \mathrm{M}\right)$ is also shown in Fig. 1 (curve c). This luminescence band is associated with single-chain excitons [10]. In addition, two other emission bands (with maxima at 550 and $660 \mathrm{~nm}$ ) are observed by diluting the stock solution $\left(10^{-3} \mathrm{M}\right)$ from $\mathrm{CHCl}_{3}$ (curve d). Luminescence band with the maximum at $550 \mathrm{~nm}$ is associated with reduction of interaction between adjacent chains caused due to diluting effect [11]. Vibrational modes are responsible for the remaining band at $660 \mathrm{~nm}$ [12]. Only this luminescence band is slightly red shifted compared to previously reported luminescence bands by Yan et al and Lui et al $[10,13]$. Excimer species in the polymer are responsible for this red shift [9]. 


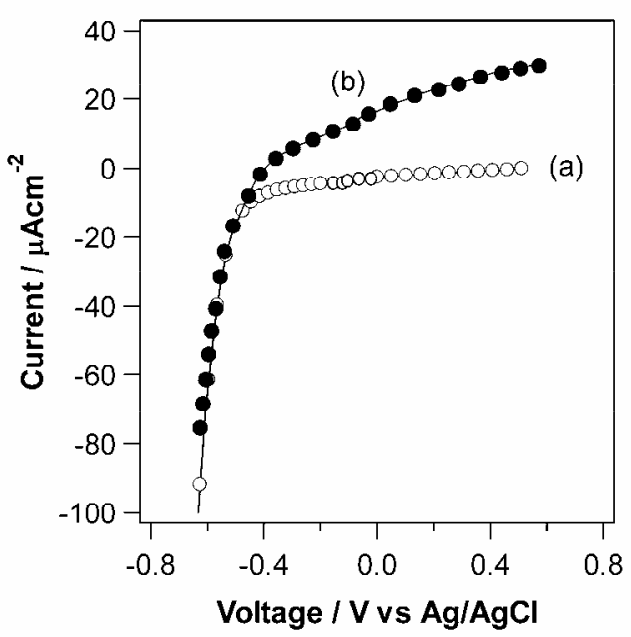

Fig. 2. Current voltage characteristics of a $\mathrm{MEH}-\mathrm{PPV} \mid \mathrm{TiO}_{2}$ electrode (a) at dark and (b) under illumination, in aqueous poly-iodide electrolyte $\left(I^{5}: I_{2}=10^{5}: 1\right)$, under three electrode configuration

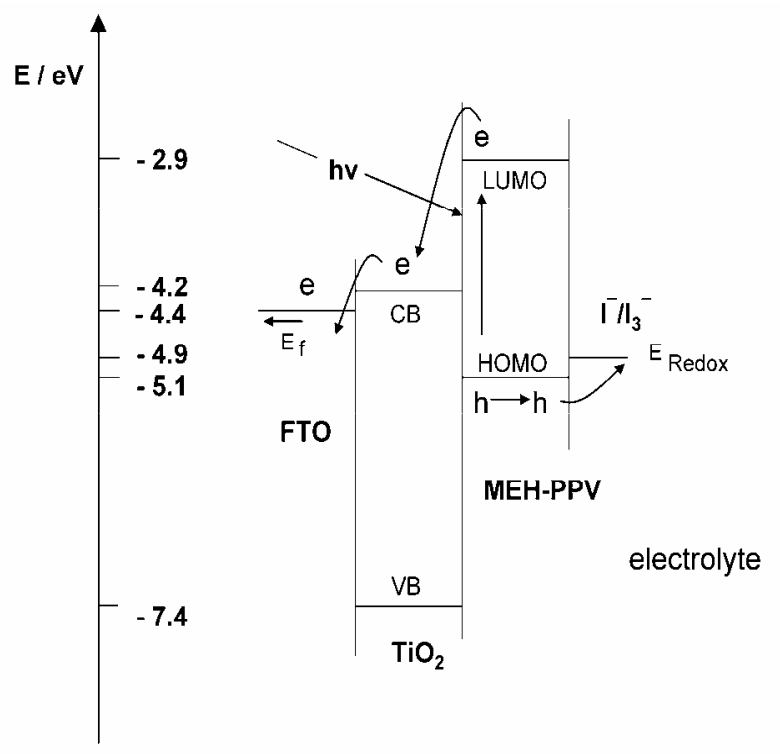

Fig. 3. Band diagram of MEH-PPV|TiO $2 \mid$ FTO electrode in polyiodide electrolyte under illumination with flat band concept. Where $\mathrm{E}_{\mathrm{f}}-$ Fermi Level of FTO, HOMO - highest occupied level of polymer, LUMO lowest occupied level of polymer, $\mathrm{CB}$ - Conduction band of $\mathrm{TiO}_{2}, \mathrm{VB}-$ Valance band of $\mathrm{TiO}_{2}$ and $\mathrm{E}_{\text {redox }}-$ redox potential of poly iodide electrolyte

\subsection{Characteristics of photo-voltaic cells with MEH-PPV as a sensitizer}

A feeble cathodic photocurrent was observed on MEH-PPV|FTO electrode, under illumination. Localization of pseudo Fermi level of MEH-PPV close to the ionization 


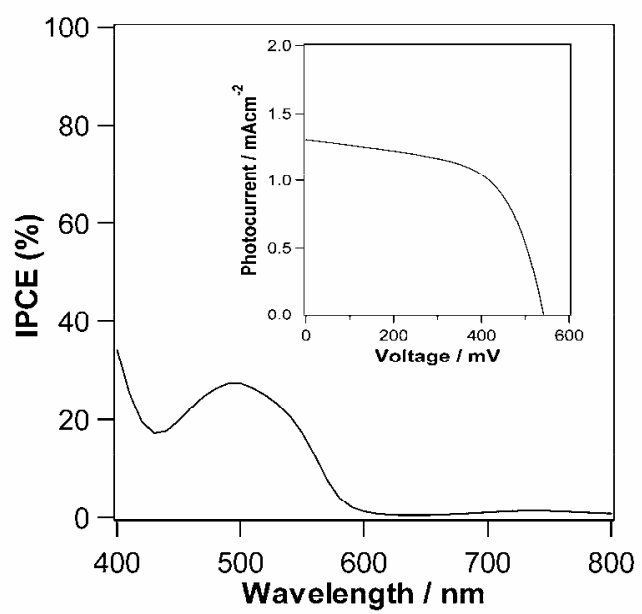

Fig. 4 IPCE spectrum of $\mathrm{TiO}_{2}|\mathrm{MEH}-\mathrm{PPV}|$ polyiodide cell, Insert shows the current voltage characteristics of the same cell, light intensity is maintained as $100 \mathrm{mWm}^{-2}$, at the electrode surface

potential (energy of HOMO level) is a reason for the generation of a cathodic photocurrent on MEH-PPV|FTO electrode $[3,14]$. It seems that the photocurrent generation takes place at polymer|electrolyte interface for MEH-PPV films and the photo-generated electrons tunnel into the electrolyte while the holes migrate toward the back contact of the electrode. However, MEH-PPV $\mid \mathrm{TiO}_{2}$ electrodes exhibit anodic sensitized photocurrent (Fig. 2). This result indicates that charge separation takes place at polymer| $\mid \mathrm{TiO}_{2}$ interface and electrons are injected into lower lying conduction band of $\mathrm{TiO}_{2}$ and holes migrate toward the polymer|electrolyte interface, under illumination. The LUMO level of MEH-PPV lies at a higher energy level than the conduction band of $\mathrm{TiO}_{2}$. Therefore, the charge injection form LUMO level to the conduction band of $\mathrm{TiO}_{2}$ is thermodynamically allowed [3]. The mechanism of charge generation of the $\mathrm{MEH}-\mathrm{PPV} \mid \mathrm{TiO}_{2}$ electrode is energetically illustrated in Fig. 3, using flat band concept. Values of work functions of $\mathrm{TiO}_{2}, \mathrm{MEH}-\mathrm{PPV}$, FTO and redox potential of $\mathrm{I}^{-} / \mathrm{I}_{3}{ }^{-}$are adopted from literature [4,15,7]. A significant enhancement in the photocurrent is observed when electrolyte sandwiches in between $\mathrm{MEH}-\mathrm{PPV} \mid \mathrm{TiO}_{2}$ and FTO electrodes. Incident-photon-to-current conversion efficiency (IPCE) of such a $\mathrm{TiO}_{2}|\mathrm{MEH}-\mathrm{PPV}| \mathrm{I}^{-} / \mathrm{I}_{3}^{-}$cell is shown in Fig. 4. Close resemblance absorption spectrum (curve a, Fig. 1) with IPCE spectrum in the visible region implies that the charge generation is by MEH-PPV in the cell. The maximum incident photon-tocurrent conversion efficiency (IPCE) of the cell is evaluated as $30 \%$ at $550 \mathrm{~nm}$. The decrease of IPCE of the in wavelength region $490-425 \mathrm{~nm}$ is attributed to the difference in the excitation depth profiles in the polymer layer [3]. The gradual increase of IPCE in shorter wavelengths than $425 \mathrm{~nm}$ is attributed to the band gap excitation of $\mathrm{TiO}_{2}$. An 
efficient recombination of photo-generated carriers via radioactive processors (intersection of absorbance and emission spectra of MEH-PPV, Fig. 1) could be one of the reasons for observed lower conversion efficiency of the cell. Non radioactive processors also decrease performance of the cell. Current-voltage characteristics of $\mathrm{TiO}_{2}|\mathrm{MEH}-\mathrm{PPV}| \mathrm{I}^{-} / \mathrm{I}_{3}{ }^{-}$cell are also shown in the inset of the Fig. 4. The maximum short circuit photocurrent of 1.3 $\mathrm{mAcm}^{-2}$ and open circuit voltage of about $543 \mathrm{mV}$ are observed for this cell, under AM 1.5 conditions.

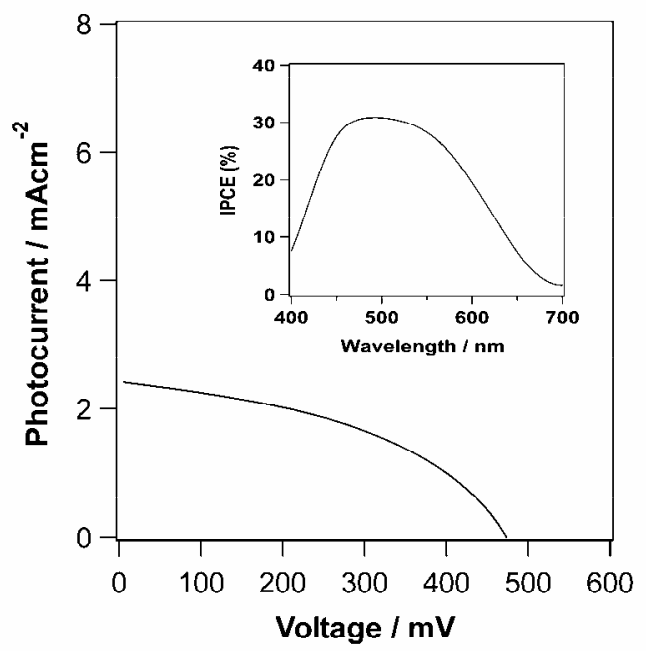

Fig. 5 Current voltage characteristics of $\mathrm{TiO}_{2}|\mathrm{~N} 3| \mathrm{MEH}-\mathrm{PPV}\left|\mathrm{I}_{2}\right|$ graphite cell under illumination of 100 $\mathrm{mWm}^{-2}$. Insert shows the IPCE spectrum of $\mathrm{TiO}_{2}|\mathrm{~N} 3| \mathrm{MEH}-\mathrm{PPV}\left|\mathrm{I}_{2}\right|$ graphite cell

\subsection{Characteristics of photo-voltaic cells with MEH-PPV as a hole conductor}

Negligible photo-properties are observed in solid-state $\mathrm{TiO}_{2}|\mathrm{~N} 3| \mathrm{MEH}-\mathrm{PPV}$ device, under illumination. However, significant enhancement in the photo-voltage is observed after exposing electrodes to iodine vapor. The resulted current is rather low and has to be improved by several fractions. It is known that applying a thin layer of graphite on polymer layer increases the electron collection efficiency of the cell toward the FTO layer [16]. Therefore, a thin layer of graphite was applied on the electrode followed by doping iodine. As expected, an enhancement was observed in the photocurrent. Current-voltage characteristic of the $\mathrm{TiO}_{2}|\mathrm{~N} 3| \mathrm{MEH}-\mathrm{PPV}\left|\mathrm{I}_{2}\right|$ graphite cell is shown in the Fig.5. A maximum open circuit photovoltage of $465 \mathrm{mV}$ is obtained for the cell. This value is close to 0.4 of attainable maximum photovoltage by this device. Maximum photovoltage of $\mathrm{TiO}_{2}|\mathrm{~N} 3| \mathrm{MEH}-\mathrm{PPV}\left|\mathrm{I}_{2}\right|$ graphite cell is determined from the energy difference of the conduction band of $\mathrm{TiO}_{2}$ and HOMO level of the polymer [3]. $\mathrm{TiO}_{2}|\mathrm{~N} 3| \mathrm{MEH}-$ $\mathrm{PPV}\left|\mathrm{I}_{2}\right|$ graphite cell exhibited maximum photocurrent of $2.4 \mathrm{mAcm}^{-2}$ under AM 1.5 
conditions. However, thickness of the MEH-PPV film was maintained not to exceed the excitation diffusion length, since this type of cells produces much higher performance when thickness of the film is equal to the magnitude of diffusion length [5]. A drastic decrement in the photocurrent of about $75 \%$ was observed in the first 20 seconds in the absence of MEH-PPV film in the cell. This result suggests that enrolment of MEH-PPV layer as an efficient electron donor in the regeneration of dye molecules. However, $\mathrm{TiO}_{2}|\mathrm{~N} 3| \mathrm{MEH}-\mathrm{PPV}\left|\mathrm{I}_{2}\right|$ graphite cell produces moderate photo-performance compared to other dye sensitized systems [6] and much higher performance than other solar cells composed of polymer hole-conducting layer [17]. Photo-properties of hetero-junctions made of polymer- $\mathrm{TiO}_{2}$ composites or blends have been reported. In these studies, MEHPPV and other polymers have been used as light harvesting analog or hole conductor it self $[3,4]$. However, we have not observed any significant performance in the cell in the absence of a sensitizer. It seems that the charge generation of this device takes place via injection of excited dye molecules. $\mathrm{TiO}_{2}|\mathrm{~N} 3| \mathrm{MEH}-\mathrm{PPV}\left|\mathrm{I}_{2}\right|$ graphite cell exhibits maximum IPCE of $35 \%$ at $500 \mathrm{~nm}$ (inset of Fig. 5). Fig. 6 illustrates the electron-transfer process of $\mathrm{TiO}_{2}|\mathrm{~N} 3| \mathrm{MEH}-\mathrm{PPV}\left|\mathrm{I}_{2}\right|$ graphite cell. Photo-performance of the cell could be further improved by increasing conductivity of the polymer.

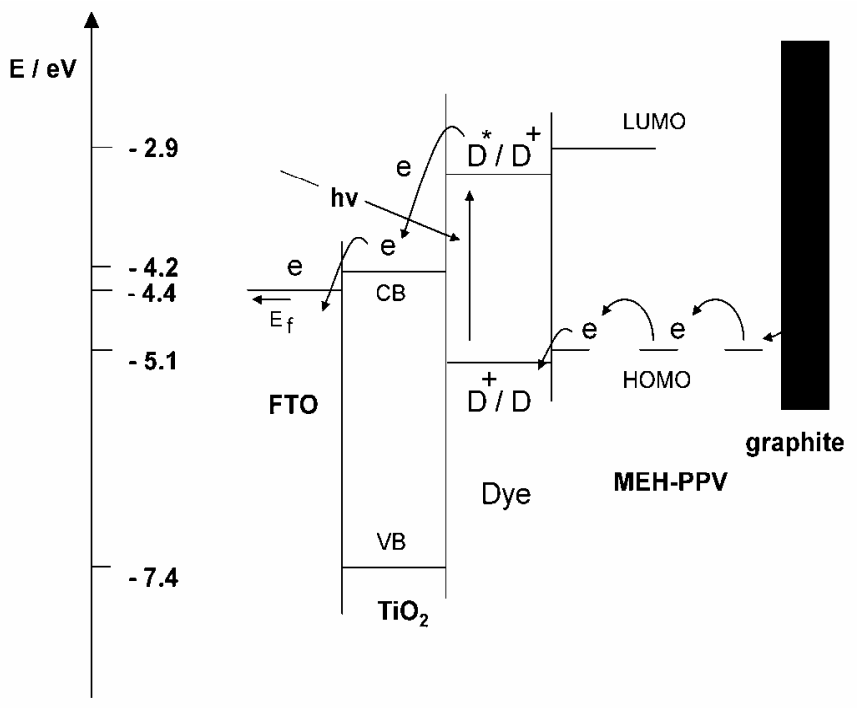

Fig. 6 Electron-transfer process of $\mathrm{TiO}_{2}|\mathrm{~N} 3| \mathrm{MEH}-\mathrm{PPV}\left|\mathrm{I}_{2}\right|$ graphite cell where $\mathrm{E}_{\mathrm{f}}-$ Fermi Level of FTO, HOMO - highest occupied level of polymer, LUMO - lowest occupied level of polymer, CB Conduction band of $\mathrm{TiO}_{2}, \mathrm{VB}-$ Valance band of $\mathrm{TiO}_{2}$, D- ground state of dye molecule, D*- excited state of dye molecule, $\mathrm{D}^{+}$- dye cation 


\section{CONCLUSIONS}

Poly [2-methoxy-5-(2-ethyl-hexyloxy)-p-phenylene vinylene] exhibits three luminescence bands in the visible region due to electron transitions in between non-localized bands, and interchain - intrachain interaction. Intrinsic and sensitized photocurrent generations are observed in MEH-PPV films when in absence and in contact with titana film. Doping of iodine slight in MEH-PPV was found to increases the conductivity and the absorbance of polymer. Maximum short circuit photocurrent of $2.4 \mathrm{mAcm}^{-2}$ and open circuit voltage of about $543 \mathrm{mV}$ were observed for photovoltaic cells fabricated by using MEH-PPV as a sensitizer and hole-conductor, respectively.

\section{REFERENCES}

1. J. H. Burroughes, D. D. C. Bradley, A. R. Brown, R. N. Marks, K. Mackay, R. H. Friend, P. L. Burns, and A. B. Holmes, Light-emitting diodes based on conjugated polymers, Nature (London) 347 (1990) 539541.

2. D. Braun, and A. J. Heeger, Visible light emission from semiconducting polymer diodes, Appl. Phys. Lett, $\underline{58}$ (1991) 1982-1984.

3. T. J. Savenije, J. M. Warman, and A. Goossens, Visible light sensitization of titanium dioxide using a phenylene vinylene polymer, Chem. Phys. Lett. 287 (1998) 148-153.

4. A. J. Breeze, Z. Schlesinger, and S. A. Cater, Charge transport in $\mathrm{TiO}_{2} / \mathrm{MEH}-\mathrm{PPV}$ polymer photovoltaics, Phy. Rew.B, $\underline{64}$ (2001) 125205-125214.

5. W. A. Daoud, and M. L. Turner, Effect of interfacial properties and film thickness on device performance of bilayer $\mathrm{TiO}_{2}$-poly(1,4-phenylenevinylene) solar cells prepared by spin coating, Reactive and Functional Polymers, $\underline{66}$ (2006) 13-20.

6. P. M. Sirimanne, T. Shirata, and T. Soga, T. Jimbo, Charge generation in a dye- sensitized solid-state cell under different modes of illumination, J. Solid State Chem., 166 (2002) 142-147.

7. H. Tributsch, Function and analytical formula for nanocrystalline dye sensitized solar cells, Appl. Phys. A, 73 (2001) 305-316.

8. Q. Qiao, J. Beck, and T. Mc Leskey, Photovoltaic devices from self-doped polymers, Proc. SPIE, (2005) 5938-5938.

9. A. Marletta, V. C. Goncalves, and D. T, Balogh, Effect of temperature on emission of MEH-PPV/PS solid-state solution, J. Luminescence, 116 (2006) 87-93.

10. M. Yan, L. J. Rothberg, F. Papadimitrakopoulos, M. E. Galvin, and T. M. Miller, Defect Quenching of Conjugated Polymer Luminescence, Phys. Rev Lett. 73 (1994) 744-747.

11. G. He, Y. Li, J. Lui, and Y. Yang, Enhanced electroluminescence using polystyrene as a matrix, Appl. Phys. Lett. $\underline{80}(2002) 4247$. 
12. R. Chang, J. H. Hsu, W. S. Fann, K. K. Liang, C. H. Chang, M. Hayashi, J. Yu, S. H. Lin, E. C. Chang, K. R. Chuang, and S. A. Chen, Experimental and theoretical investigations of absorption and emission spectra of the light-emitting polymer MEH-PPV in solution, Chem. Phys. Lett. 317 (2000) 142-152.

13. J. Lui, Y. Shi, and Y. Yang, Improving the performance of polymer light-emitting diodes using polymer solid solutions, Appl. Phys. Lett., 79 (2001) 578-580.

14.P. M. Sirimanne, E. V. A. Premalal, P. K. D. D. P. Pitigala, and K. Tennakone, Utilization of MEH-PPV as a sensitizer in titana-based photovoltaic cells, Solar Energy Mat. \& Solar Cells, $\underline{90}$ (2006) 1673-1679.

15.Q. Qiao, L. Su, J. Beck, and J. T. Mc Leskey, Characteristics of water-soluble poly- thiophene polythiophene: $\mathrm{TiO}_{2}$ composite and its application in photovoltaics, J. Appl. Phys. 98 (2005) 094906094913.

16. T. Kitamura, M. Maitani, M. Matsuda, Y. Wada, and S. Yanagida, Improved solid-state dye solar cells with polypyrrole using a carbon-based counter electrode, Chemistry Letters (2001) 1054-1055.

17. U. Bach, D. Lupo, P. Comte, J. E. Moser, F. WeissÖretel, J. Salbeck, H. Spreitzer, and M. Gratzel, Solidstate dye sensitized mesoporous $\mathrm{TiO}_{2}$ solar cells with high-photon-to -current-conversion efficiency, Nature, $\underline{395}$ (1998) 583-585. 